\title{
Glück auf, der Steiger kommt: a frame account of extensional and intensional steigen
}

\author{
Thomas Gamerschlag, Wilhelm Geuder \& \\ Wiebke Petersen
}

\begin{abstract}
*
The paper investigates the meaning variation of the German movement verb steigen ('climb'/'rise'). Three major uses are contrasted within a frame-based analysis: steigen as a verb of manner of motion, as a verb of directed movement and as an intensional verb. The modeling in terms of Barsalou frames, i.e., in terms of functional attributes and their values, allows an explicit account of the correlations that hold among subevents, manner, positions and the overall path traversed by the theme argument, and yields a representation of the event structure and the argument structure with flexible granularity. By investigating the variation in the attribute structure of the verb steigen in the extensional and intensional uses we give an analysis that captures the relation between the uses as a transfer of the relevant attributes from verb-frame-internal attributes in the extensional use to verb frame-external attributes which are realized by functional nouns such as Temperatur 'temperature' in the intensional use. Thereby, we offer an account of the polysemy of steigen which goes beyond the usual picture of a metaphor.
\end{abstract}

* The research presented in this paper was supported by the CRC 991, funded by the German Research Foundation (DFG). Moreover, we are grateful to three anonymous reviewers for their insightful questions and valuable suggestions. 


\section{Introduction ${ }^{1}$}

The empirical domain addressed in the present paper is the meaning variation found in spatial and abstract senses of movement verbs, specifically the German verb steigen. On the whole, this verb belongs to the same lexical field as English climb, which has generated some amount of discussion in the literature on verb semantics (from Fillmore 1982b and Jackendoff 1985 up to Levin \& Rappaport Hovav 2013). However, the case of steigen is somewhat more complex because the meaning spectrum is richer: steigen encompasses meanings that can variously be translated into English as climb, rise, and to some extent step. The four major uses illustrated in (1) can be distinguished.

(1) steigen

a. as a verb of manner of motion

Sebastian stieg aufeinen Berg.

S. climbed on a mountain

'Sebastian climbed a mountain.'

b. as a verb of directed motion

Der Ballon stieg.

the balloon climbed

'The balloon was climbing.'

c. as a static verb of "fictive motion"

Die Straße steigt langsam (an).

the road climbs slowly PART

'The road climbs slowly upwards.'

d. as an intensional verb of change along a property scale

Die Temperatur der Flüssigkeit steigt.

the temperature of.the liquid is rising

'The temperature of the liquid is rising.'

Here, our main objective is to elucidate the relationship between the uses as a movement verb, especially as a verb of directed movement, and the intensional variant. A frequently cited example of the intensional use is The temperature is

1 In the wake of the first version of this paper, numerous requests have been voiced that we should translate or explain the obscure German line in its title. However, given that it is a cultural item that largely eludes translation, and given that Sebastian may have immediately noticed the most important conceptual relations between Glück auf and Glückwunsch, we feel we may refrain from addressing this issue in depth. The following may be helpful, though: http://www.youtube.com /watch?v=lwz_dfxpeKo. 
ninety and rising (in the German version of this, rise would translate as steigen) - and the classic puzzle arising from it is that the temperature may be said to be ' $90^{\circ}$ ', but ' $90^{\circ}$ ' cannot be said to be rising (cf. Montague 1973, Jackendoff 1979 , Löbner 1981). While in most of the literature authors have capitalized on the intensionality effect associated with the subject of the construction, we want to focus here on the conditions in the lexical semantic representation of the verb that enable such uses. In doing this, we will also point out the connections that relate this use to the other variants of steigen which do not translate as rise. (Although interesting in itself, the third variant is outside the scope of the present paper).

As for the theoretical domain of investigation, it turns out that the analysis of extensional and intensional steigen is at the intersection of a whole number of issues that have been central concerns throughout Sebastian Löbner's work: it touches on the topic of intensional verbs and functional concepts, both of which are already keywords of his 1979 dissertation, as well as on his recent endeavors at advancing frame theory as a tool for semantics (Löbner 2014). Beginning with the earlier strand of work, it is to be noted that the subject in an intensional use of steigen is precisely a functional noun in the sense of Löbner (1985), i. e., a noun that refers to a function which relates an explicitly or contextually given carrier of an attribute to a unique value (at each point of time). In Die Temperatur des Wassers steigt ('The temperature of the water is rising'), 'water' is assigned the attribute TEMPERATURE whose value is increasing during the event time of rising.

In the latter strand of work mentioned above, Sebastian Löbner has put forward two fundamental hypotheses about cognition and conceptual representations: (1) "The human cognitive system operates with a single general format of representations [and (2)] ... this format is essentially Barsalou [1992] frames”, (Löbner 2014: $23 \mathrm{f}$.). Frames represent concepts in terms of a network of functional attributes and their values (instead of, say, feature sets or sets of entailments). Hence, one can say that "[f]unctional concepts constitute the representational 'vocabulary' of categorization" (Löbner 2011b:14). One task that we are facing now is to represent event categories, e. g., the lexical meanings of our movement verbs, in terms of such frame structures. What is more, however: with intensional steigen/rise, we begin to see an interplay of the use of functional concepts in the architecture of the verb's representation and the appearance of a functional concept as the subject argument of this verb (as in The temperature (of the water) is rising). This double appearance of functional concepts, both as the denotation 
of argument expressions and as components inside the frame representation of verbs, has been emphasized in Löbner (2011b: 18) as being of general significance:

"If Barsalou is correct in assuming that the basic structure of all concepts in human cognition is frames, then functional nouns represent the type of concepts which our entire cognition is based on. Attribute concepts, i. e., instances of functional concepts, form the structure of the mental representations in our cognitive system: we categorize whatever we categorize in terms of functional concepts."

What we would like to offer, therefore, in an attempt to add to this general program laid out in the quotations, is an investigation of the variation in the attribute structure of the verb steigen in its different uses, in connection with an investigation of the shift between functional concepts occurring either in the verb's meaning or in the verb's arguments, depending on the lexical variant at hand.

We will proceed as follows: in Section 2 we set out the differences in the uses of steigen as a manner of motion verb and as a verb of directed motion. A framebased analysis of these uses is provided in Section 3, which also contains a brief general introduction to this representation format. The intensional variant of steigen is the topic of Section 4 where it will be analyzed as based on the directed motion reading. Finally, Section 5 provides a brief summary and outlook.

\section{Manner of motion and direction of motion in the semantics of steigen}

Diachronically, the underlying sense of steigen seems to have been something like 'step'/'walk'/'stride'. According to Grimm's dictionary (Grimm 1971, s.v. steigen), the verb is related to Greek $\sigma \tau \varepsilon i$ $\chi \omega$ ('stride, climb') [Grimm's translation: 'schreiten, steigen'], Sanskrit stighnōmi ('stride') and Old Irish tíagaim ('walk'). It can thus be assumed that the other readings have historically developed out of a manner of movement sense. However, in present-day German a semantic connection between the manner use and the other uses is no longer obvious, and this is already one of the main problems in the analysis of its lexical meaning.

As a first step in the analysis, we want to separate a variant in which steigen denotes a directed movement from a variant which denotes manner of movement. In the classification of Levin (1993), the English verb climb already occurs with a double classification of this kind; and in more recent work, Levin \& Rappaport Hovav (2013) have elaborated on the idea that climb has these two lexical senses. We do not want to defend an alternative analysis for climb here, but nev- 
ertheless would like to point out that it is especially German steigen which shows signs of such a polysemy, which climb at least does not exhibit as clearly. One argument for a polysemy of steigen emerges from an observation pointed out in Geuder \& Weisgerber (2008) according to which the manner component of steigen is much more specific than that of the English verb climb. Consider the following paradigm:

(2) a. $\sqrt{ }$ Die Ziegen stiegen aufs Dach.

the goats climbed onto.the roof

$\sqrt{ }$ The goats climbed onto the roof.

b. ?? Die Schnecke stieg auf die Pflanze.

the snail climbed onto the plant

$\sqrt{ }$ The snail climbed onto the plant.

c. ?? Der Zug stieg auf den Berg.

the train climbed onto the mountain

$\sqrt{ }$ The train climbed the mountain.

d. $\sqrt{ }$ Das U-Boot stieg an die Oberfläche.

the submarine climbed to the surface

$\sqrt{ }$ The submarine climbed towards the surface.

e. $\sqrt{ }$ Der Ballon stieg höher und höher.

the balloon climbed higher and higher

$\sqrt{ }$ The balloon climbed higher and higher.

The examples are arranged in terms of a gradient that runs from a very palpable manner component in terms of the use of limbs in (a), to interpretations involving more indistinct movements of the whole moving entity as in (b) and (c), and further to uses involving a freely suspended object without extremities in the last examples. In all cases, English climb may be used. In view of this dense distribution of variants along the gradient just sketched, Geuder \& Weisgerber conclude that the underlying lexical meaning of climb merely specifies force exertion in upward direction while everything else comes in via inferences about additional properties of the manner component according to specific contexts (cf. also the discussion in Levin \& Rappaport Hovav 2013: 59ff.). In our view, it is not clear whether a cut-off point could be found, marking the distinction envisaged by Levin \& Rappaport Hovav between a manner sense and a direction sense of climb: would the disappearance of a manner feature be seen as happening between (c) and (d), or between (d) and (e)? Be this as it may, German steigen does 
show a disruption in the distribution, and hence gives evidence of two lexical variants. We interpret the last two uses of steigen as involving a pure verb of directed movement, in line with the fact that the English examples in (d) and (e) are the variants in which the meaning of climb is especially hard to tell apart from the purely directional verb rise; Levin \& Rappaport Hovav (2013: 65) therefore assume both to be directional verbs (however, Geuder \& Weisgerber 2008 argue that a manner-direction distinction can be maintained).

What is important for the analysis of the manner variant is that the attempts to use steigen in (b) and (c) are unacceptable. The reason seems to be that the manner variant which is called for contains a restriction that an entity is moving on its legs. Example (b) is not merely unacceptable but ridiculous, precisely because it is felt to presuppose that snails have legs. By and large, steigen can be predicated of all moving entities that could be said, in a stative snapshot, to be "standing" on their legs. This condition holds for those uses which imply ground contact; however, as soon as there is reference to a freely suspended entity, as in (d) and (e), usage of steigen is no longer constrained in the same way, and hence we conclude that we are dealing with a different lexical variant. Another observation on the manner features associated with steigen mentioned in Geuder \& Weisgerber (2008) points in the same direction: in some uses it is translated by English step as in (3) below.
a. Er stieg über die Pfütze.
He stepped over the puddle. he stepped over the puddle
b. Er stieg
auf die Leiter.
1. He climbed the ladder. he stepped/climbed onto the ladder
2. He stepped onto the ladder.

These examples show that steigen can be instantiated by one single step, provided that there is some remarkable vertical movement of the legs associated with that step (for the example 'stepping over a puddle' we would imagine people lifting their leg to some extent). Here again, we see a manner component that is sufficiently similar to the one that produced a deviance with (2b) and (c) above: steigen is about movement supported by legs, with a feature of upward force exertion associated to it (although the walk-type uses of steigen in (3) might be considered as involving some amount of polysemy).

A second argument for the existence of an independent directional variant of steigen comes from the interaction with directional modifiers. It is typically expected of manner verbs that they should be neutral with respect to a direction 
feature and therefore, they should be able to stand on their own in order to express just the manner feature, or optionally to allow combination with all kinds of directionals, even downward directionality, as in Die Ziegen stiegen vom Dach (herunter) 'The goats climbed (down) from the roof'. Examples (2d) and (e), in contrast, cannot be used to refer to downward direction. These latter examples occur in uses without directional complement, but this time they imply a direction even in isolation, hence display a different lexical sense. This is the main criterion used by Levin \& Rappaport Hovav (2013) to distinguish a manner variant and a direction variant.

With respect to German steigen, we find the somewhat unexpected restriction that a directional complement is actually necessary in the manner reading. (There are only a few unproductive agent nominalizations that use steigen in the direction-independent way expected from a manner verb, such as Bergsteiger 'hillclimber' and the strongly lexicalized Steiger 'foreman of miners'). However, the putative directional variant behaves as expected, and so, eventually, the distinction between two meaning types is confirmed in the sense that the complementation behavior differs as shown in (4):
a. Sebastian stieg auf den Berg.
S. climbed onto the mountain
Sebastian climbed the mountain.
b. ? Sebastian stieg den ganzen Tag.
S. climbed the whole day
Sebastian was climbing the whole day long.
c. Der Ballon stieg.
the balloon climbed
The balloon was climbing.
d. Der Ballon stieg höher und höher
the balloon climbed higher and higher
The balloon was climbing higher and higher.

Example (4d) shows a modifier applying to directional steigen. This case reminds us of an observation in Rappaport Hovav (2008: 22f.), according to which verbs which lexically incorporate a scale are only able to combine with complements modifying that scale, rather than with complements introducing any new scale; hence, $(4 \mathrm{~d})$ can be seen as an indication that a scale of vertical position is part and parcel of the verb meaning in this use (see Fleischhauer \& Gamerschlag, in press, for a tentative treatment of steigen in this use). Apparently the scalarity of steigen 
in this variant leads to difficulties in using it with a goal PP. We see a minimal contrast in the following set of examples, in that, for instance, the addition of bis ('until/up to'), which contributes an extended portion of a vertical path to the goal description, saves the otherwise awkward example in (5a) below.

a. ? Der Ballon stieg unter die Decke / ...neben die Laterne. the balloon climbed under the ceiling next.to the lantern intended: 'The balloon climbed up to the ceiling / next to the lantern.'

b. $\sqrt{ }$ Der Ballon stieg bis unter die Decke / ...bis neben die the balloon climbed until under the ceiling until next.to the Laterne.

lantern

'The balloon climbed up as far as the ceiling / until it was next to the lantern.'

This contrast could be explained by positing that directional steigen refers to paths in terms of an orientational feature (namely an absolute "upward" direction indicated by the direction of gravity), and that it does not, in contrast to the manner reading, involve a positioning of an object in terms of a reference object (which would be given for the manner variant of steigen by the entity that supports the 'standing' configuration required by the manner feature).

To conclude this section, we have pointed out the existence of two polysemic variants of steigen: a manner variant can be clearly singled out due to its very specific meaning of 'making steps (with some vertical component)' - which is actually still fairly close to its etymological origins mentioned at the outset - and also due to its inability to occur without a directional complement. We are then left with a separate variant denoting directed movement without manner, i.e., movement in upward direction.

\section{Components in the frame representation of steigen: manner, path, and event structure}

In the following, we will confront the manner of motion and the directed motion variants of steigen by discussing their frame representations, starting with a brief introduction into the representational format. Then, by means of these variants, we will demonstrate the flexibility of the frame format which accounts for the power of frame theory. Frames allow one to zoom into conceptual structures to any desired degree and to unify lexical and general conceptual representations. 
Additionally, it is possible to represent interrelations between fundamentally different domains like time and space in an adequate fashion.

\subsection{Frames: some basics}

In Petersen (2007), a formal account of frames for nominal concepts is given which represents them by graphs built up from attributes as transition functions between nodes. In this way, the central role of functional concepts which was mentioned in the introduction is captured. Nodes represent objects and their respective attribute values.
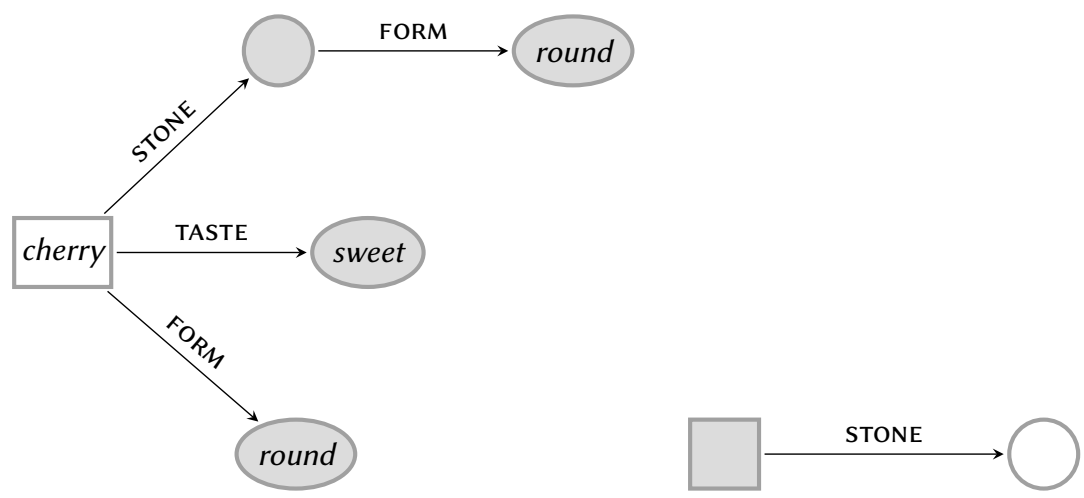

Figure 1: Frames for nominal concepts: sortal concept cherry (left), functional concept stone (right).

Figure 1 gives two examples of nominal frame graphs. The graph on the left represents the frame for the sortal concept cherry. Here a cherry is characterized by its sweet taste, its round form and the round form of its stone. The graph on the right represents the frame of the functional concept stone of something. A stone (in this sense) is an object for which something must exist of which it is the stone. The arcs in the frame graphs are labeled by attributes, i. e., by partial functions denoted by functional concepts, and the graph nodes are labeled by types. $^{2}$ The latter are often left unspecified if they are determined by the context. For example, the nonlabeled node in the left frame graph could be typed by stone since values of the attribute sTONE must be stones. In a logical notation, types correspond to one-place predicates and attributes to unary functions. Rectangular nodes represent open frame arguments and the central node which represents the

2 We assume that types are ordered in a type hierarchy which specifies for each type its admissible attributes. 
referent of the frame is marked by not being shaded grey. The two frame graphs in Figure 1 can be translated into the following lambda expressions (predicate constants are written in italics and function constants in small capitals; open argument nodes introduce lambda-bounded variables; for more details on this translation see Petersen \& Osswald 2014):

(6) a. (cherry, sortal)

$$
\begin{aligned}
& \lambda x . \operatorname{cherry}(x) \wedge \operatorname{round}(\operatorname{FORM}(\operatorname{sTONE}(x))) \wedge \operatorname{sweet}(\operatorname{TASTE}(x)) \wedge \\
& \operatorname{round}(\operatorname{FORM}(x)) \quad \text { [logical type: }<e, t>\text { ] } \\
& \text { b. (stone, functional) } \lambda x \iota y . y=\operatorname{stone}(x) \quad \text { [logical type: }\langle e, e>\text { ] }
\end{aligned}
$$

Comparing the graph-based frame representations in Figure 1 with their translations into lambda expressions in (6), we would like to point to the following advantages of the former representation format: first, Löbner's fundamental idea that attribute concepts constitute the basic components of cognitive concept formation is explicitly built into the graph-based representations, as it are the arcs which connect nodes and thereby span the frames. Second, the graph-based representation is variable-free and thereby better suited as a cognitive representation. We believe that 'thinking' is more about drawing connections than about building a register of variables. A further related advantage of the graph-based representation is that it is more flexible than the logical one since it does not presuppose a language of predicates of fixed arity with a fixed argument order but rather allows for addressing arguments by attributes.

So far the frame account, sketched above, has been proven useful in representing concepts belonging to different static concept types and in modeling their compositional semantics. In a recent study, Naumann (2013) extends this approach to capture dynamic concepts of actions and events. We will now apply his ideas in the modeling of the meaning of steigen.

\subsection{Frames for events}

To represent the different variants of steigen, it is first of all necessary to clarify the issues that arise with respect to the representation of manner. In the recent literature, there has been a lively discussion of "manner-result complementarity", i. e. the hypothesis that verbs specifying manner features and verbs specifying direction features should form a dichotomy, excluding hybrid verbs that contain both specifications simultaneously (cf. Levin \& Rappaport Hovav 2013 and earlier related work). It is important to note that this discussion concerns a level of lexi- 
cal representation which, in the context of the frame model we are employing, can be seen as the starting configuration for a process of constructing a full-fledged cognitive representation of a situation. Hence, in a frame model, lexical entries and conceptual representations do not appear as qualitatively different things. We tentatively assume here that manner-result complementarity indeed holds for the division of steigen into different lexical senses, i.e., a pure manner sense and a pure directional sense. However, the frame model allows for dynamic elaboration of its attribute structure in the course of interpretation, i. e., enrichment with more fine-grained specifications. Therefore, the frame model forces us to decide on whether certain attributes should count as admissible in principle even if they do not figure in the "lexical" configuration. Resolution of this issue ultimately has to await a general theory of (adverbial) modification in the frame format. For the specific case at hand, we can state the following: the manner use of steigen has already been found to select for a directional complement, and it is well-known that manner verbs can be elaborated into manner + direction descriptions in the syntax in certain (especially the Germanic) languages. From the fact that this process obeys restrictions that are part of the syntactic and/or semantic composition rules of a specific language, we tentatively conclude that the frames of manner verbs and directional verbs cannot unconditionally be augmented by attributes of the opposite sort but that representations exempt from manner-result complementarity have to be constructed from special rules of frame composition. With steigen the case is unproblematic, since a directional complement is selected as an argument anyway. In the same vein, we believe that any elaboration of the frame in the directional variant by way of manner features will have to be licensed by special construction rules, which we do not seek to develop here. This is why, in the lexical representation, we do not provide attributes of directional steigen that foreshadow the appearance of any manner components (and it is also evident that "manner" never occurs as an argument selected by a verb, which would give rise to the mirror image of manner steigen).

Let us now turn to the task of constructing a frame representation specifically for steigen. In the tradition of "frame semantics" in the sense of Fillmore, frames are used to model the static dimensions of events (Fillmore 1982a), i.e., their relations to objects participating in the event. The frame in Figure 2 shows the static dimensions of steigen as a manner of motion verb (henceforth steigen $_{\mathrm{mm}}$ ).

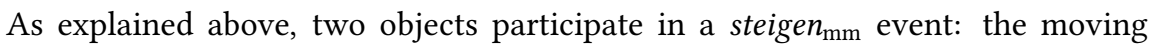
object which is linked to the central frame node by the THEME attribute and the 
path along which the object moves i.e., the value of the PATH attribute. The value specifications of both attributes correspond to arguments at the level of semantic composition and hence must be provided by linguistic composition. This is indicated by the rectangular shape of their nodes in the frame graph. Such nodes will be called argument nodes. Two further attributes of steigen $n_{\mathrm{mm}}$ are MANNER and EVENT STRUCTURE; they differ from the former in that their values are part and parcel of the verb meaning and neither can be nor need to be provided by the context. (As stated above, adverbial modification is still an option for elaborating a frame but will not be treated here). In a first approximation, these two attributes appear as global properties of the event in the representation in Figure 2:

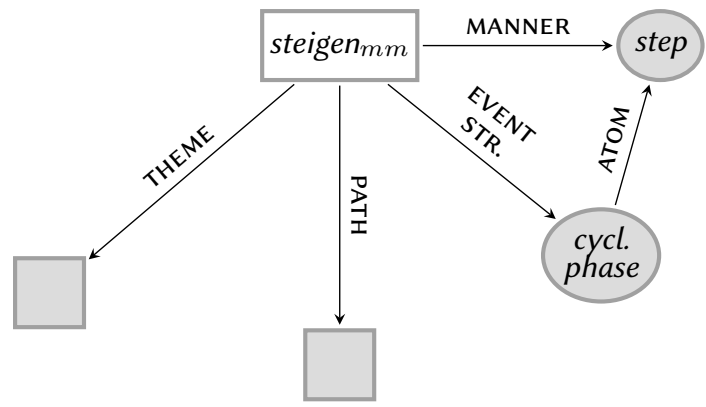

Figure 2: Static event frame of $s t e i g e n_{\mathrm{mm}}$.

By zooming into the values of MANNER and EVENT STRUCTURE, however, the dynamic aspects of steigen ${ }_{\mathrm{mm}}$ events are revealed. ${ }^{3}$ Events have a temporal structure, that is, they evolve over a time period. Events with cyclic phase structure are cumulative and have an event structure that is made up of atoms (cf. Rothstein 2004, chapter 8 , on the role of atoms in the constitution of activities). An event $\mathrm{e}$ is of a cumulative event type if it does not change its type when a repetition is added (type(e) $=$ type $\left(e e^{*}\right)$ ). It is made up of atoms if it can be decomposed into a series of proper subevents $e_{1} \ldots e_{n}$ of one type such that: type $\left(e_{i}\right)=\operatorname{type}\left(e_{j}\right)$ for all $i, j \in$

3 For simplicity we use the term zooming here for two different operations: (1) for 'refinements' in which attribute values are further specified by attribute value pairs, and (2) for 'temporalizations' which assign event decompositions to static event frames (see Naumann 2013 for more details). Possible refinements are determined by the type of the attribute value and by the constraints attached to it in the type signature. Temporalizations are determined by the type of the event which is as well given by its position in the type signature. Thus, it would be more adequate to type the central node of the steigen $_{\mathrm{mm}}$ frame with a subtype of cyclic phase structure, but in order to keep our frame graphs simple and to improve readability we do not discuss type signatures here and store the information about the type of the event structure as a separate attribute value pair. 
$1, \ldots, n$ and type $\left(e_{i}\right) \neq$ type $(e)$ and none of the subevents $e_{i}$ has a proper subevent $\mathrm{e}^{\prime}$ of the same type, type $\left(\mathrm{e}_{\mathrm{i}}\right) \neq$ type $\left(\mathrm{e}^{\prime}\right)$. An event has a continuous phase structure if it is cumulative and its event structure is not made up of atoms.

Figure 3 shows the details of the event structure of steigen $_{\mathrm{mm}}$. Given that the manner description we have argued for in Section 2 contained "steps", these function as atoms of the activity which will be iterated over the course of the event. This relation between the event structure of steigen sm $_{m}$ and its manner component is modeled in Figure 2 by the ATOM attribute of the EVENT STRUCTURE value.

On the event decomposition (ED) level the event is decomposed into single step subevents. This level represents the temporal structure of the event and links it to the level of the described situation, the participating objects, and their roles in the event. The linking between the ontologically different levels is given by a zoom function $(Z)$ or bridge in the sense of Blackburn \& De Rijke (1997). Each temporally extended event $e$ on the ED level is bounded by two boundary events $\alpha(\mathrm{e})$ (left boundary) and $\beta$ (e) (right boundary) whose runtimes are singletons (cf. Piñón 1997). Nonboundary events are linked to global properties of the event, termed "static event frames" (SEF) in Naumann (2013). In this case, the SEFs represent single step events (cf. the SEF level in Figure 2). Boundary events, in turn, are linked to situation frames (SF) which are built up from the frames for the objects involved in the event. In the given example, the only involved object is the one who steps, hence the value of the THEME of step. The SFs specify the relevant information about the moving object, namely its position. ${ }^{4}$ The SF level in the figure below provides snapshots of the moving object at different time points of the event.

After having analyzed the temporal event structure of steigen $_{m m}$, we will now zoom into the manner component of the SEF in Figure 1. A steigen mm $_{\text {event }}$ consists of a series of step events. A step event contributes its own SEF with one theme argument. Additionally, steps can be characterized by a specific FORCE CONSTELlation leading to a special step movement (see Figure 4, top).

The value of the FORCE CONSTELLATION of step is depicted in Figure 4 (bottom). It is a noticeable, upwards-directed force (STRENGTH : 》0, DIRECTION : upwards)

${ }^{4}$ Events may involve more complex SFs. For example, the SFs for Mary gives fohn the book are composed of three object frames (one for Mary, one for John, and one for the book). The first and the last SF differ in that in the first SF Mary is the value of an attribute POSSEssor attached to book, while in the last $\mathrm{SF}$ this value is fohn. 
SEF LEVEL:
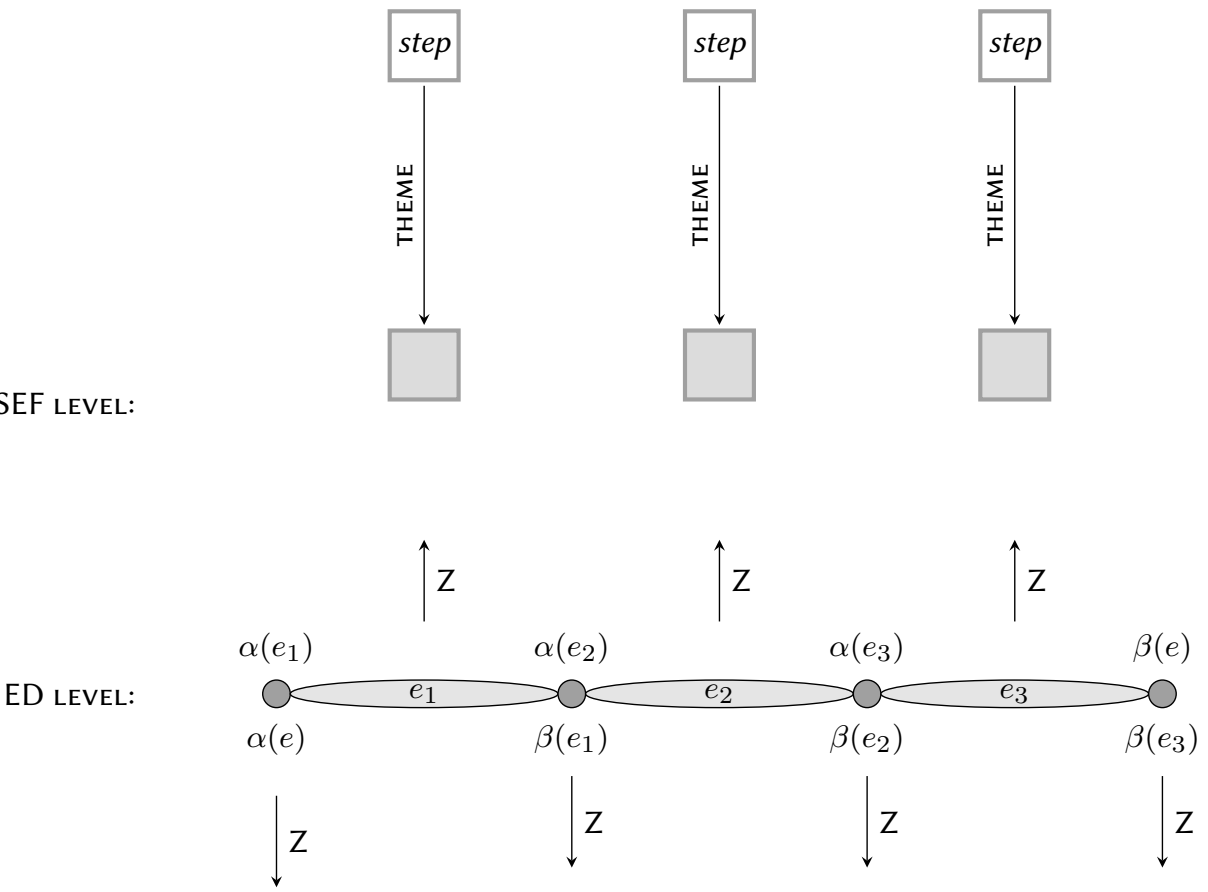

SF LEVEL:

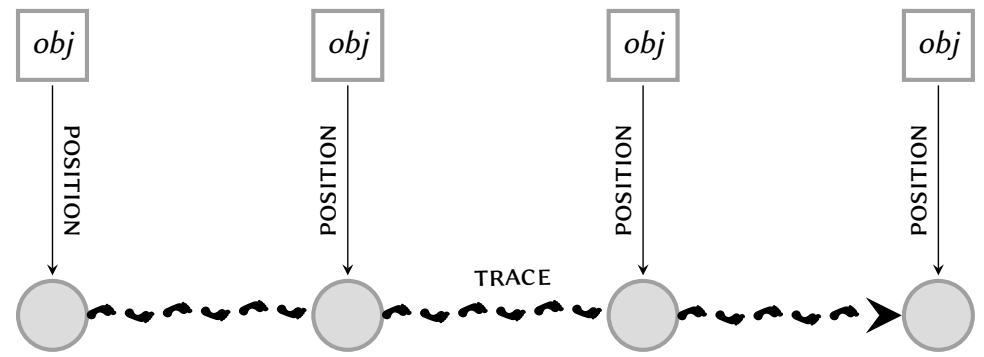

Figure 3: Event structure of steigen $n_{m m}$. 

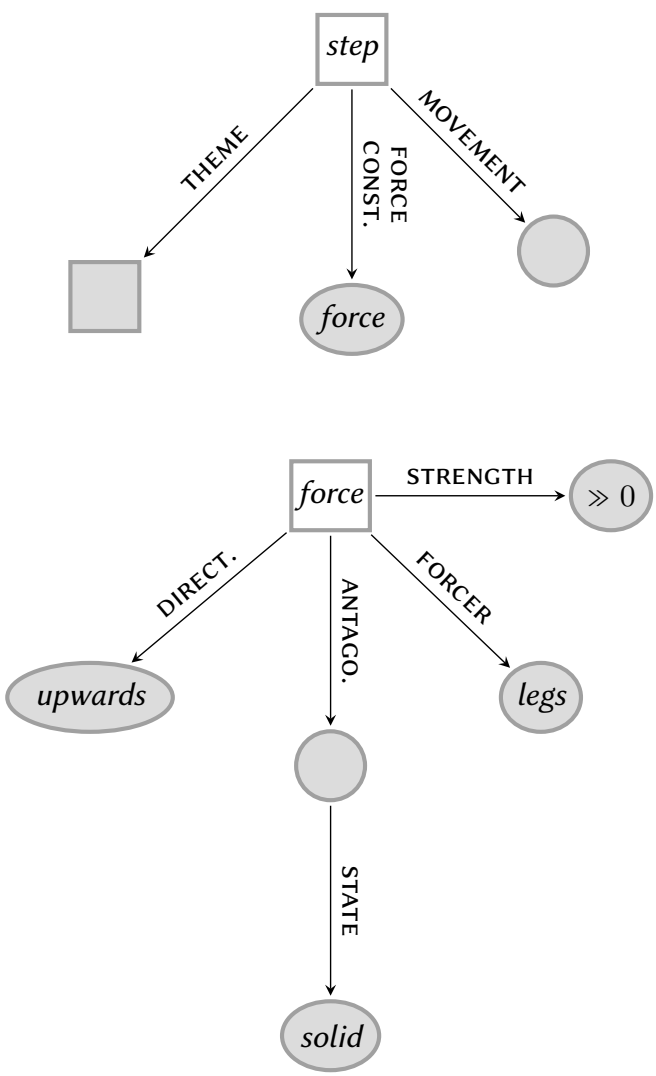

Figure 4: Zooming into the manner component of steigen ${ }_{m m}$. 
that is exerted by legs against a solid antagonist (FORCER : legs, ANTAGONIST : STATE : solid).

The frames from the preceding figures can be composed into a single steigen $n_{\mathrm{mm}}$ frame, exhibiting the correlations between the attribute values (Figure 5). The composition is controlled by constraints like "the theme of an event with a cyclic event structure is coreferential with the theme of the atoms of the event structure", which are not subject of this paper. Note that there is now a LEGS attribute linking the theme of step and steigen ${ }_{m m}$ to the legs node coming from the force frame. ${ }^{5}$ Since LEGs is a functional concept, the legs node needs to be the value node of a LEGS attribute. And given that the only possible node in the frame which could carry a LEGS attribute is the THEME value node, the attribute is attached to this. Thus, by specifying the force constellation of a step event, the theme value of steigen $_{m m}$ events gets restricted to entities with legs, excluding manner of motion readings of Der Ballon steigt in die Höhe.

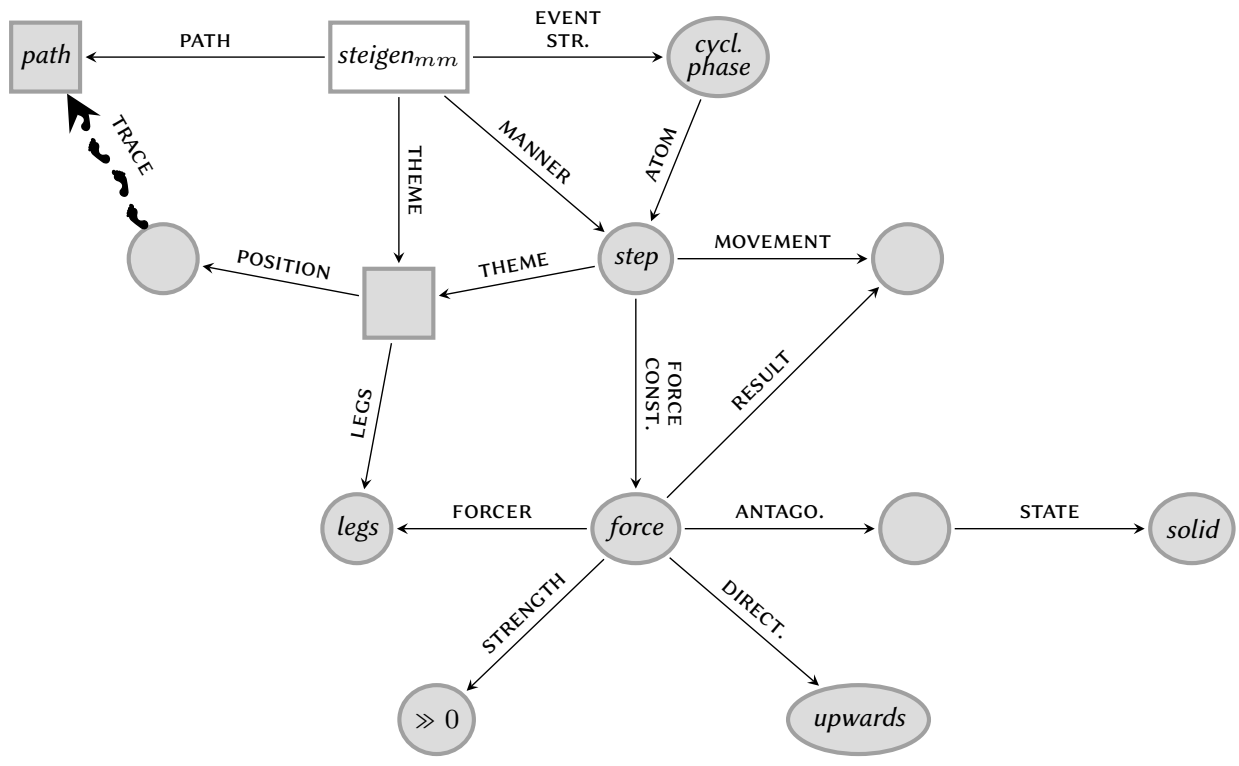

Figure 5: Detailed frame of steigen $n_{m m}$.

A special case is the TRACE attribute linking the position of the THEME of steigen $_{\mathrm{mm}}$ to its PATH specification. Here, TRACE is a dynamic attribute that is projected into

5 The problem of intermixing entity-valued with pair-valued attributes lies outside the scope of this paper. 
this frame from the event decomposition frame in Figure 3 and maps the POSITION of the THEME value to the record of its trace in the time span of the event. Note that although paths are static objects, traces are not. Paths are directed spatial entities that can be modeled as "continuous functions from the real unit interval to positions in some model of space" (Zwarts 2005: 748); thus, they are non-temporal structures. In contrast, a trace is a function from the time span of an event into the value space of an attribute of one of the participants of the event (here, the POSITION of the THEME participant) (cf. also Eschenbach et al. 2000). Hence, spatial traces like traces of object positions are temporal in the sense that each position point is indexed by a time stamp. Only the image of the function trace restricted to the full time span of the steigen $_{\mathrm{mm}}$ event gives the path of the event.

This architecture also instantiates a basic distinction between two independent tiers: "translational movement", i. e., change of location in space, and, to be kept separately from it, potential "internal movements", i. e., movements that entirely pertain to the manner domain. In our case, the stepping movement, as it occurs in the manner description of steigen, will be classified as an object-internal movement rather than a translational movement. It is the result of a special force constellation exerted by the legs. The translational movement proceeds along the PATH, specified, for example, by the PP in Die Ziegen stiegen aufs Dach 'The goats climbed onto the roof'. Given that paths as directed spatial entities have no temporal dimension, it is the POSITION TRACE of the THEME of steigen that denotes the translational movement. ${ }^{6}$ Although the force has to have an upward component in steigen situations, the path need not: a movement that opposes itself to gravity may still result in horizontal or even downward movement.

In contrast to a manner of motion verb, the use of steigen as a verb of directed movement $\left(\right.$ steigen $\left._{\text {dir }}\right)$ appears without a manner component and hence with a pure theme argument that changes its position in space. We get the following simplified frame decomposition in Figure 6 (left).

The PATH attribute now has a fixed value, which can perhaps be motivated from a stereotype of upward movement associated with the manner use of steigen (cf. Levin \& Rappaport Hovav 2013). Since the semantic distance between directional and manner variants is fairly large anyway, due to the complete absence of the

6 This difference becomes important if one investigates the use of steigen as a static verb, as in Das Gelände steigt an 'The terrain rises'. Here, a state is described which does not evolve over time and thus no trace of an object is given and no translational movement occurs. However, we still have a path component which is now embedded as a spatial entity into the spatial entity Gelände 'terrain, land'. 

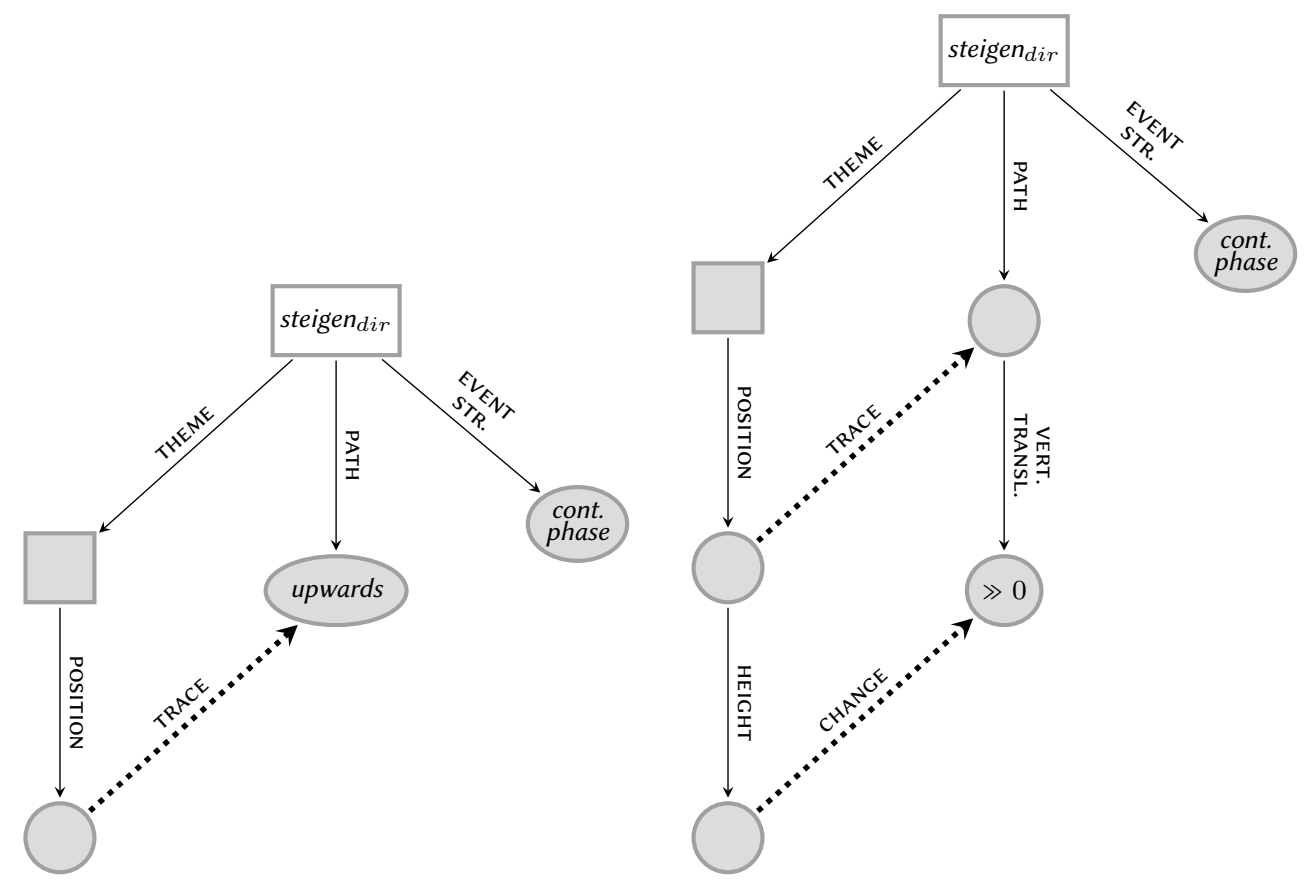

Figure 6: Simplified frame of the directed motion use of steigen.

very richly specified manner component, we do not attempt to sketch any mechanism that claims a regular meaning extension. However, note that the same direction specification - "upwards" - has occurred in the frame of the manner of motion use of steigen as the specification of the force direction (cf. Figure 5).

With regard to the upwards component of steigen $_{\text {dir }}$, we can also be more detailed: the frame in Figure 6 (right) results from zooming into the "upwards" node. As can be seen, an UPWARDS path means that the VERTICAL TRANSLATION of the movement is greater than zero. This in turn implies that the HEIGHT of the POSITION of the moving entity changes accordingly over the running time of the steigen event. Formally, this is captured by the dynamic attribute CHANGE which requires that the difference in HEIGHT at the beginning and the end of steigen $n_{\text {dir }}$ is greater than zero.

However, note what now happens to the relationship between event structure, theme, and path. With the absence of the manner component, we also lose the atoms that yielded a cyclic event structure. Therefore, this time the event structure must be dense (unless information that comes in via semantic composition 
indicates otherwise, e. g., by means of a modifier like stepwise). The path component can still be modified by directional PPs that provide reference objects, these then could provide localizations of the theme during certain stretches of the event structure as illustrated in (7).

(7) Der Ballon stieg über die Baumwipfel (hinaus).

the balloon rose above the treetops (beyond)

'The balloon rose above (and beyond) the treetops.'

The meaning here is that there is a nonfinal portion of the path (presumably also noninitial) on which the balloon is localized at the same absolute height as the treetops. In the absence of such modifiers, we retain a bare linear ordering which says that with increasing progression of the event we get positions at least as high as the previous ones. In the manner variant, a directional PP would also provide a reference object, and points of the path would have to be localized in a way relative to this object that needs to be determined by contextual inference. For instance, in (8) the reference object Zaun 'fence' triggers a construal according to which an initial portion of the path has upward direction, a medial portion is on top of the fence, and a final portion has downward direction. This construal is driven by our world knowledge of how we would interact with this type of obstacle (given the constraints imposed by the preposition).

(8) Sebastian stieg über den Zaun.

S. climbed over the fence

'Sebastian climbed over the fence.'

So, to sum up, we find that with the manner variant, properties of the reference object influence the directionality of the path (interacting with the prepositional meaning). With the directional variant, it is rather the other way round: path PPs merely act as modifiers of a path whose primary description has already been established.

\section{Intensional steigen}

The readings of steigen illustrated so far all refer to vertical motion in space while they differ primarily with respect to the presence of a manner component. As illustrated by the examples in (9), there is also a figurative use of steigen which abstracts away from spatial motion. In this use the movement along a vertical path originally expressed by steigen is related to abstract "motion" along a scale. 
(9) a. Die Temperatur der Flüssigkeit steigt.

the temperature of.the Liquid rises

'The temperature of the liquid is rising.'

b. Der Preis des Apartments steigt.

the price of.the apartment rises

'The price of the apartment is rising.'

c. Der Druck in der Kabine steigt.

the pressure in the cabin rises

'The pressure in the cabin is rising.'

(examples taken from Fleischhauer \& Gamerschlag, in press)

In all of the examples above, the subject noun, instead of simply denoting a moved object (a theme), introduces a scale. For instance, Temperatur (der Flüssigkeit) 'temperature (of the liquid)' in (9a) refers to the temperature of the liquid which can be specified by a particular degree on the temperature scale. Likewise, Preis 'price' and Druck 'pressure' in (9b) and (c) denote the price and pressure of an entity which can be explicated by a degree on the price and pressure scales, respectively. If steigen 'rise' is combined with a scale-denoting noun like Temperatur 'temperature', we assume that the noun contributes a new scale. Steigen then indicates that there is some abstract movement along this scale such that the degree or "position" on the scale at the end of the steigen event is greater or "higher" than at the beginning.

As already stated at the beginning of the paper, the figurative use of steigen in (9) can be characterized as an intensional use (Montague 1973, Löbner 1979, 1981) since it involves a total change of the subject referent over time. As a result, replacing the subject with an expression which refers to the denotation of the subject at a specific point of time yields an awkward sentence such as \#90 Grad Celsius steigen lit. '90 degrees Celsius are rising'. This is opposed to the partial change characteristic of the extensional use in which case the reference of the subject does not change. Thus, the uses of steigen introduced in the preceding sections can all be regarded as extensional since the subject referent only changes with respect to a single dimension, namely its spatial location. As a contrast to the intensional use, the subject can be replaced by an expression with the same reference as in the sentence Das Luftfahrzeug steigt 'The aircraft is rising' in which Ballon 'balloon' has been replaced by the coreferring expression Luftfahrzeug 'aircraft'. 
The figurative relation between upward movement and increasing scale values is well recognized in the literature on metaphor and reflected, for example, in Lakoff \& Johnson's (1980) conceptual metaphor formula 'up is more/down is less.' The use of the metaphor is not restricted to verbs but also systematically exploited by nouns (e.g., die Höhe der Temperatur lit. 'height of the temperature'), adjectives (e.g., die Temperatur ist hoch 'the temperature is high'), and prepositions (e. g., Temperaturen über dem Gefrierpunkt 'temperatures above freezing point'). In spite of their intuitive correctness, metaphor approaches in the tradition of Lakoff \& Johnson are usually vague when it comes to structural and representational issues. By contrast, our approach is based on frame representations with a focus on structural differences between the extensional and intensional uses of steigen.

If the origin of steigen $_{\text {ins }}$ lies in a verb of vertical movement, we can now see how this restricts its combination with nouns in the subject position, to the effect that the noun must introduce a scale. More precisely, it must express a function which maps a given argument (realized as a genitive possessor of the noun or understood from the context) onto the value of a particular scale. For instance, the head of the noun phrase Temperatur der Flüssigkeit 'temperature of the liquid' in (9a) denotes a function which maps the referent of the genitive possessor der Flüssigkeit 'of the liquid' to a degree on the temperature scale. Scale-denoting nouns like Temperatur are natural language expressions of functional concepts in the sense of Löbner (2011a). Functional nouns are characterized by unique reference, i. e., for a given argument (at a given time) they single out a unique value. Scalar nouns form a subclass of functional nouns, but there are also functional nouns which express concepts whose values are not ordered scalarly. For instance, Vater 'father' and Geburtsort 'place of birth' also refer to functional concepts which, however, do not have a scalar value range. By consequence, these nouns cannot combine with steigen in the intensional use.

As shown in (10), there are also some scalar nouns which cannot combine with steigen. All of the nouns in (10) make reference to spatial properties which are clearly of a scalar nature such as the circumference and the width of an object. However, the combination of concrete spatial meaning contributed by the respective nouns and abstract spatial meaning introduced by the intensional verb seems to be excluded. In spite of the origin of steigen $_{\text {ins }}$ in steigen $_{\text {dir }}$, even the combination of Höhe 'height' and steigen $n_{\text {ins }}$ is ruled out. 
(10)

*Der Umfang / / die Fläche / die Breite / die Höhe steigt.

the circumference the area the width the height rises

lit.: 'The circumference/area/width/volume/height is rising.'

If steigen is substituted by zunehmen 'increase', a verb which does not derive metaphorically from vertical movement, the sentence becomes fine as shown in (11).

\section{Der Umfang / die Fläche/die Breite / die Höhe nimmt zu. the circumference the area the width the height increases 'The circumference/area/width/volume is increasing.'}

In addition, the use of intensional steigen is restricted with respect to the direction of change. As illustrated by (12), it can only express an increase along the respective scale as in (a) but never a decrease as intended in (b).
a. Die Temperatur steigt von 3 auf 10 Grad. the temperature is.rising from to degrees 'The temperature is rising from 3 to 10 degrees.'
b. *Die Temperatur steigt von 10 auf 3 Grad. the temperature is.rising from to degrees intended: 'The temperature is rising from 10 to 3 degrees.'

The restriction to change in an "upward direction" groups intensional steigen together with the use of steigen as a verb of directed motion, which is also confined to upward movement, and sets these two uses apart from the manner of motion use, which also allows for reference to downward motion. The three uses can be ordered according to the degree of abstractness with the use as a manner of motion verb as the most concrete one, the use as a verb of directed motion as a use which abstracts away from manner but still denotes motion in space, and the intensional use which makes reference to abstract motion along a scale. Since both directional and intensional steigen lack manner information while at the same time being restricted to upward movement, it seems plausible to consider directional steigen as the source concept underlying the metaphor resulting in intensional steigen.

The frame for intensional steigen as in die Temperatur steigt 'the temperature is rising' is given in Figure 7 below. As can be seen, the frame is almost identical to the frame for steigen in the directed motion use in Figure 6 above: it retains much of the structure of the source concept. 


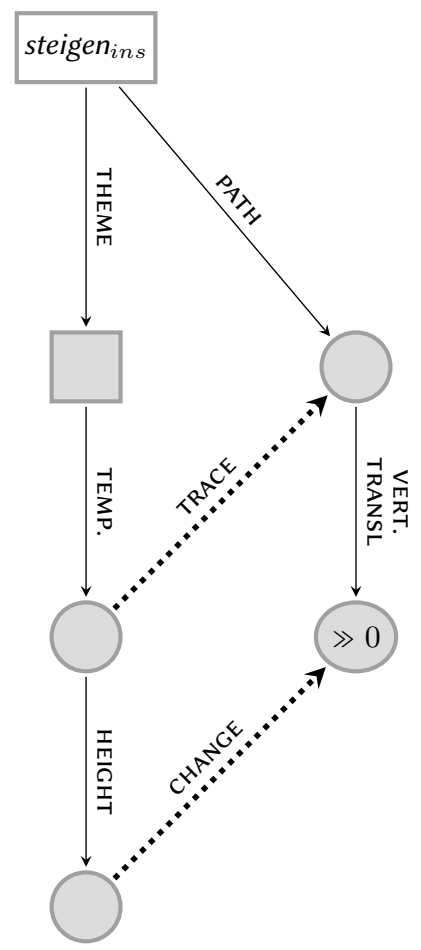

Figure 7: Frame representation of die Temperatur steigt 'the temperature is rising'.

In Figure 7, the position attribute of directional steigen has been replaced by the scalar attribute TEMPERATURE contributed by the functional noun Temperatur. As with the preceding uses of steigen, we assume that the value change which takes place during the steigen event is summed up in the form of a trace defined in terms of values with a temporal ordering. This trace is an abstract object which can be conceived as a path through the value space determined by the dimension that comes with the particular attribute (e. g., TEMPERATURE, PRICE, PRESSURE). As a consequence, the frame shown in Figure 7 still exhibits a PATH attribute whose value is identical to the value of the dynamic attribute TRACE. Moreover, the change in height literally expressed by the directional use of steigen is reflected in the presence of the HEIGHT attribute which maps the value of TEMPERATURE, PRICE, PRESSURE, etc. on its respective (abstract) HEIGHT on the corresponding scale. Note that this conception of the HEIGHT attribute entails that the attribute is not restricted to the spatial position of an object as in the directional use. By contrast, we conceive of HEIGHT as a more abstract function which returns scale 
degrees in dependence of the entity it applies to. As in the preceding use, the total change in HEIGHT during the course of the event is restricted to a value greater than zero in order to ensure an increase. Again, the total change of HEIGHT over the event time is identified with the vertical translation of the value trace. The frame representation of intensional steigen before combining it with an adequate functional noun is given in Figure 8, in which FC is a placeholder for the attribute introduced by the functional noun.

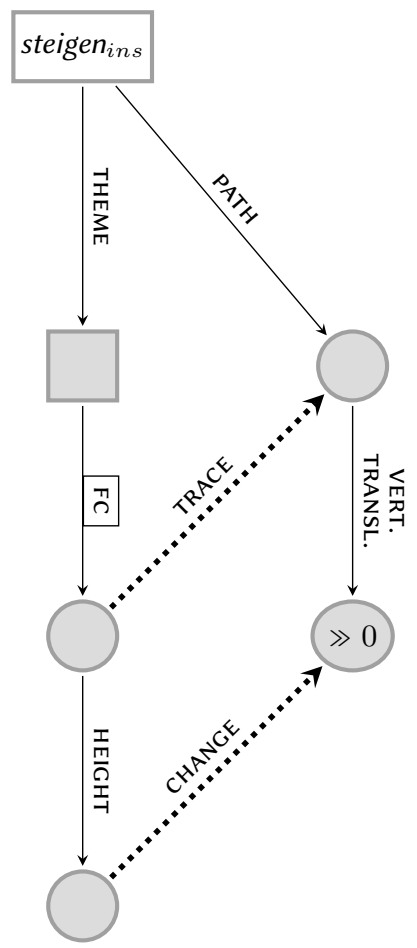

Figure 8: Frame representation of intensional steigen 'rise'.

In the frame in Figure 8, neither the theme argument nor the particular attribute whose values change during the steigen event are stated. Consequently, the frame has two open parameters: one open argument node and one open arc argument. ${ }^{7}$ When steigen combines with a functional noun, the missing attribute is specified by the noun. Simultaneously, the theme argument of steigen is identified with

7 These different types of arguments would correspond to an individual argument and a higher-order argument in a predicate logic representation of steigen $_{\text {ins }}$. 
the genitive possessor argument of the noun. Consider, for instance, the complex noun phrase Temperatur der Flüssigkeit 'temperature of the liquid' which is represented by the frame in Figure 9.

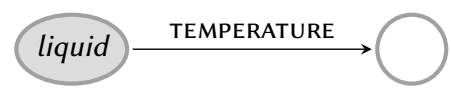

Figure 9: Frame representation of Temperatur der Flüssigkeit 'temperature of the liquid' .

As a functional concept 'temperature' has an open argument node for the entity which is mapped onto its unique temperature value. From the argument node, the arc labeled with the attribute encoded by the functional noun leads to the central node which specifies what the frame is above (see Petersen \& Osswald 2014, for a detailed frame analysis of genitive constructions). As stated above, intensional steigen has an open argument node as well as an open arc argument which need to be specified by the subject taken by the verb. Because of their property of encoding a single attribute for an open argument, functional nouns are suited for contributing the information required in the frame of intensional steigen shown above. Thus, when the complex noun phrase Temperatur der Flüssigkeit 'temperature of the liquid' combines with steigen, it contributes both the attribute TEMPERATURE and the theme argument Flüssigkeit 'liquid' which undergoes a change with respect to temperature. Note that by identifying the DP-internal possessor argument with the theme argument of the verb, it becomes an argument of the complex verb consisting of intensional verb and functional noun (for further discussion of the combination of different types of functional nouns and intensional verbs see Fleischhauer \& Gamerschlag, in press).

The fact that steigen only selects functional nouns with a scalar value range is achieved by the HEIGHT attribute which requires that the function it is applied to exhibits a scalar order of values. However, as shown by the examples in (10) above, functional nouns denoting spatial dimensions such as Breite 'width' and Fläche 'area' are ruled out as well, even though they have scalar value ranges. Functional nouns of this type can be excluded by assuming a type hierarchy for the types denoted by the functional nouns that occur as subjects of steigen $_{\text {ins. }}$. In principle, this type hierarchy would distinguish between scales that allow for making reference to their (abstract) height and those that do not. For the sake of simplicity, we will not elaborate on that issue here.

The frame analysis of steigen + Temperatur can also be applied to the change of state verb (sich) erwärmen 'warm' illustrated in (13). 
(13) Die Flüssigkeit erwärmt sich.

the liquid warms REFL

'The liquid is warming up.'

The verb erwärmen, which is represented by the frame in Figure 10, also refers to a positive value change along the temperature scale. ${ }^{8}$

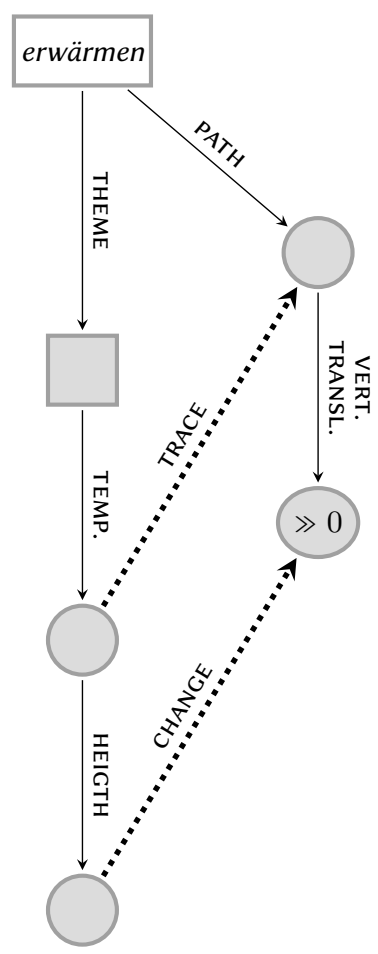

Figure 10: Frame representation of erwärmen 'warm'.

As can be seen, the frame for erwärmen is identical to the frame for die Temperatur steigt in Figure 7 above. Yet, in contrast to steigen + Temperatur, the attribute TEMPERATURE is already part of the verb meaning and does not need to be contributed by a functional noun. Consequently, the theme is not introduced as a

8 Although the frame in Figure 10 does not make explicit reference to the deadjectival origin of erwärmen, the derivation of erwärmen from the adjectival base warm 'warm' is reflected by the fact that both are represented by frames containing TEMPERATURE as a core attribute with the difference that the frame for the adjective does not address a value change. Likewise, we assume that the frames for the antonyms abkühlen 'cool (down)' and kalt 'cool' also build on the central attribute TEMPERATURE (cf. Kennedy \& McNally 2005 for the assumption that antonymous adjectives involve the same dimension/attribute). 
DP-internal possessor either, but rather realized as the subject of the verb. Since the frame above is a conceptual representation, it does not reflect the different grammatical realization of the theme argument. We do not aim here at a theory of how the mapping of natural language to conceptual frames is accomplished. Since this would require embedding frame representations as a conceptual level into a full-fledged grammatical model with an elaborate linking module, it would surely go beyond the scope of this paper. In principle, however, models such as HPSG (Pollard \& Sag 1994), which also apply recursive attribute-value structures, are particularly well-suited for combining with conceptual frame representations due to their structural affinity.

\section{Conclusions and outlook}

In this paper, we have offered a first attempt at a frame analysis of a climb-type movement verb, German steigen. The modeling in terms of Barsalou frames allowed us to delineate the event structure and the argument structure in every detail, especially the correlations that hold among subevents, manner, positions and the overall path traversed by the theme argument. Based on this representation, we have explored the ways in which intensional uses of steigen come about. The crucial point was to show the interplay of the lexical representation of the verb and the semantic type of the nominal argument, which denotes a functional concept. Going beyond received ideas that steigen in this use involves a metaphorical transfer from movement in space to a value scale, we were able to show how functional concepts internal to the event frame in the concrete readings are delegated to the nominal argument in the scalar use. Among other things, this makes it possible to explain the role of genitive arguments of the theme of steigen as well as the selection restriction imposed by this variant of the verb. Clearly, a number of questions surrounding this case remain to be addressed, among them the question of possible differences between directional verbs (like rise) and manner verbs (like, perhaps, climb) with respect to polysemic extensions such as the intensional use. We proposed tracing back the intensional use to a purely directional verb meaning, hence it remains to be clarified to which extent intensional uses of manner verbs are possible. 


\section{Bibliography}

Barsalou, L. 1992. Frames, concepts, and conceptual fields. In A. Lehrer \& E. Feder Kittay (eds.), Frames, fields, and contrasts: New essays in semantic and lexical organization, 21-74. Hillsdale, NJ: Lawrence Erlbaum Associates Publishers.

Blackburn, P. \& M. De Rijke. 1997. Zooming in, zooming out. Fournal of Logic, Language and Information 6 (1). 5-31.

Eschenbach, C., L. Tschander, C. Habel \& Lars Kulik. 2000. Lexical specification of paths. In C. Freksa, W. Brauer, C. Habel \& K. F. Wender (eds.), Spatial cognition, vol. II, 127-145. Berlin: Springer.

Fillmore, C. 1982a. Frame semantics. In Linguistics in the morning calm, 111-137. Seoul: Hanshin Publishing Co. The Linguistic Society of Korea.

Fillmore, Charles. 1982b. Toward a descriptive framework of spatial deixis. In Robert Jarvella \& Wolfgang Klein (eds.), Speech, place and action: Studies in deixis and related topics, 31-59. London: John Wiley.

Fleischhauer, J. \& T. Gamerschlag. in press. We're going through changes: How change of state verbs and arguments combine in scale composition. Lingua special issue 'Argument realization in morphology and syntax'.

Geuder, W. \& M. Weisgerber. 2008. Manner of movement and the conceptualization of force. Talk presented at the workshop Il y a manière et manière, Université d'Artois, Arras, France. http://semanticsarchive.net/Archive/Tk5Ym EwN/MannerMovement_slidescompact.pdf.

Grimm. 1971. Deutsches Wörterbuch von Jacob und Wilhelm Grimm. 16 Bände in 32 Teilbänden. 16 Bände in 32 Teilbänden. (1854-1961). Leipzig edition, 1971. Available online: http://woerterbuchnetz.de/DWB/.

Jackendoff, R. 1979. How to keep ninety from rising. Linguistic Inquiry 10. 172176.

Jackendoff, R. 1985. Multiple subcategorization and the $\theta$-criterion: The case of climb. Natural Language and Linguistic Theory 3. 271-295.

Kennedy, C. \& L. McNally. 2005. Scale structure and the semantic typology of gradable predicates. Language 81 (2). 345-381.

Lakoff, G. \& M. Johnson. 1980. Metaphors we live by. Chicago: Chicago University Press.

Levin, B. 1993. English verb classes and alternations. Cambridge MA: MIT Press.

Levin, B. \& M. Rappaport Hovav. 2013. Lexicalized meaning and manner/result complementarity. In B. Arsenijević, B. Gehrke \& R. Marín (eds.), Studies in the composition and decomposition of event predicates, 49-70. Dordrecht: Springer. 
Löbner, S. 1979. Intensionale Verben und Funktionalbegriffe. Zur Syntax und Semantik von 'wechseln' und den vergleichbaren Verben des Deutschen. Tübingen: Narr.

Löbner, S. 1981. Intensional verbs and functional concepts: More on the "rising temperature” problem. Linguistic Inquiry 12 (3). 471-477.

Löbner, S. 1985. Definites. Journal of Semantics 4. 279-326.

Löbner, S. 2011a. Concept types and determination. Journal of Semantics 28(3). 279-333.

Löbner, S. 2011b. Functional concepts and frames. http://semanticsarchive.net /Archive $\bigwedge \backslash$ jl1NGEwO/.

Löbner, S. 2014. Evidence for frames from human language. In T. Gamerschlag, D. Gerland, R. Osswald \& W. Petersen (eds.), Frames and concept types: Applications in language and philosophy. Studies in Linguistics and Philosophy 94, 23-67. Dordrecht: Springer.

Montague, R. 1973. The proper treatment of quantification in ordinary English. In J. Hintikka, J. Moravcsik \& P. Suppes (eds.), Approaches to natural language. proceedings of the 1970 stanford workshop on grammar and semantics, 221-242. Dordrecht: Reidel.

Naumann, R. 2013. Outline of a dynamic theory of frames. In G. Bezhanishvili, S. Löbner, V. Marra \& F. Richter (eds.), Logic, language, and computation, vol. 7758 Lecture Notes in Computer Science (LNCS), 115-137. Berlin, Heidelberg: Springer.

Petersen, W. 2007. Decomposing concepts with frames. Baltic International Yearbook of Cognition, Logic and Communication 2. 151-170.

Petersen, W. \& T. Osswald. 2014. Concept composition in frames - focusing on genitive constructions. In T. Gamerschlag, D. Gerland, R. Osswald \& W. Petersen (eds.), Frames and concept types: Applications in language and philosophy. Studies in Linguistics and Philosophy 94, 243-266. Dordrecht: Springer.

Piñón, C. 1997. Achievements in an event semantics. Proceedings of semantics and linguistic theory 7. 276-292.

Pollard, C. \& I. Sag. 1994. Head-driven phrase structure grammar. Chicago: University of Chicago Press.

Rappaport Hovav, M. 2008. Lexicalized meaning and the internal temporal structure of events. In S. Rothstein (ed.), Theoretical and crosslinguistic approaches to the semantics of aspect, 13-42. Amsterdam: John Benjamins.

Rothstein, S. 2004. Structuring events: A study in the semantics of lexical aspect. Oxford: Blackwell Publishing. 
Zwarts, J. 2005. Prepositional aspect and the algebra of paths. Linguistics and Philosophy 28 (6). 739-779.

\section{Authors}

Thomas Gamerschlag

Wilhelm Geuder

Wiebke Petersen

Departement of Linguistics and Information Science

Heinrich-Heine-University Düsseldorf

\{gamer,geuder,petersen\}@phil.hhu.de 